\title{
Protective effect of dexpanthenol against cisplatin-induced hepatotoxicity
}

\author{
YILMAZ BILGIC ${ }^{1}$, SAMI AKBULUT $^{2}$, ZEYNEP AKSUNGUR $^{3}$, MEHMET ERMAN ERDEMLI $^{4}$, \\ ONURAL OZHAN $^{5}$, HAKAN PARLAKPINAR $^{5}$, NIGAR VARDI $^{6}$ and YUSUF TURKOZ ${ }^{3}$ \\ Departments of ${ }^{1}$ Gastroenterology, ${ }^{2}$ Surgery and Liver Transplant Institute and ${ }^{3}$ Biochemistry, \\ Inonu University Faculty of Medicine, Malatya 44280; ${ }^{4}$ Department of Biochemistry, Nigde Omer Halisdemir University \\ Faculty of Medicine, Nigde 51240; Departments of ${ }^{5}$ Pharmacology and ${ }^{6}$ Embryology and Histology, \\ Inonu University Faculty of Medicine, Malatya 44280, Turkey
}

Received March 5, 2018; Accepted July 13, 2018

DOI: $10.3892 /$ etm.2018.6683

\begin{abstract}
The aim of the present study was to investigate the protective effect of dexpanthenol (Dexp) against cisplatin (Cis)-induced hepatotoxicity. Thirty-two Sprague Dawley rats were divided into four groups: Control group $(n=8)$, Dexp group ( $\mathrm{n}=8,500 \mathrm{mg} / \mathrm{kg} / \mathrm{ip} /$ daily single dose/3 days Dexp), Cis group $(\mathrm{n}=8,7 \mathrm{mg} / \mathrm{kg} / \mathrm{ip} /$ single dose Cis) and Cis+Dexp group $(\mathrm{n}=8$, $500 \mathrm{mg} / \mathrm{kg} / \mathrm{ip} /$ daily single dose $/ 3$ days Dexp $+7 \mathrm{mg} / \mathrm{kg} / \mathrm{ip} / \mathrm{single}$ dose Cis). MDA, CAT, GSH, GSH-Px, TOS, TAS, OSI, Total Nitrit, IL-1 $\beta$, IL- 6 and TNF- $\alpha$ levels were analyzed in liver tissue samples. After paraffinization of liver tissue samples, histopathological (congestion, loss of glycogen, number of Kupffer cells) and immunohistochemical (caspase-3 expression) parameters were assessed on the paraffinized liver sections. GSH, TAS, TOS, OSI, Tot Nit, L-Arginine, ADMA and SDMA levels were measured in the serum samples. Statistically significant differences were found between the groups in terms of all liver tissue biochemical parameters, with the exception of IL- $1 \beta$ and TNF- $\alpha$ levels. GSH, CAT, GSH-Px, TAS and Tot Nit levels were significantly higher in the Cis+Dexp group compared to the Cis group, whereas MDA, TOS, OSI and IL-6 levels were higher in the Cis group. Similarly, serum GSH, TAS, Tot Nit levels were higher in the Cis+Dexp group whereas TOS, L-Arginine, ADMA and SDMA levels were higher in Cis group. There were statistically significant differences between Control and Cis groups in terms of congestion increase, increase of glycogen loss, increase of Kupffer cell number and increase of caspase-3 expression $(\mathrm{P}<0.001)$. There was a statistically significant difference between the $\mathrm{Cis}$ and the Cis+Dexp groups in terms of histopathologic parameters, with the exception
\end{abstract}

Correspondence to: Dr Sami Akbulut, Department of Surgery and Liver Transplant Institute, Inonu University Faculty of Medicine, Elazig Yolu $10 \mathrm{Km}$, Malatya 44280, Turkey

E-mail: akbulutsami@gmail.com

Key words: cisplatin, hepatotoxicity, dexpanthenol, antioxidant potential of congestion $(\mathrm{P}<0.001)$. To conclude, histopathological, immunohistochemical, and biochemical results of this study demonstrated that Dexp has a protective effect against Cis-induced hepatotoxicity.

\section{Introduction}

Cisplatin (Cis), whose antineoplastic efficacy was discovered in 1960s, is a platinum-derivative antineoplastic agent used to treat a variety of solid organ tumors such as testis, ovaries, urinary bladder, head and neck, brain, and lungs (1-5). Despite its potent antineoplastic efficacy, Cis's toxic side effects during treatment such as nephrotoxicity, neurotoxicity, ototoxicity, myelosuppression, hepatotoxicity limits its clinical use (1-5). Studies investigating the relationship between Cis dose and toxic side effects have mostly suggested a correlation between Cis's cumulative dose and toxic side effects. This is particularly prominent for the liver and hematopoietic system (1-6). However, it has been shown that hepatotoxicity may also develop after a single dose or low repeated doses (1).

Although there is no consensus as to the mechanism of Cis-induced hepatotoxicity, the two most widely recognized views are the shift of the antioxidant balance towards oxidative stress and acceleration of apoptosis $(1,3,7)$. Cells exposed to oxidative stress eliminate reactive oxygen species (superoxide, hydroxyl, hydrogen peroxide) and reactive nitrogen species [nitric oxide (NO), nitrogen dioxide, and peroxynitrite] by using endogenous enzymatic antioxidants (SOD, GSH-Px, CAT, GSR), endogenous nonenzymatic antioxidants (GSH, thioredoxin, melatonin), and exogenous antioxidants (ascorbic acid, $\alpha$-tocopherol, retinol, $\alpha$-carotene, $\beta$-carotene, lycopene, cryptoxanthin, zinc, copper, manganese, iron, selenium, flavonoids, phenols, phenolic acid, lignins, tannins). Experimental studies using many antioxidants, free radical scavengers, and natural herbal compounds have been conducted to prevent Cis's side effects without limiting its antineoplastic efficacy. Other than the above-mentioned antioxidants, antioxidant substances including apocynin, thymoquinone, naringenin-oxime, curcumin, silymarin, resveratrol, gingko, phosphomycine, sodium thiosulfate, n-acetyl-cysteine, methionine, taurine, and dexpanthenol (Dexp) have been most heavily studied in the literature. 
Dexp is a pantothenic acid (PA) analogue oxidized to PA in peripheral tissues. PA and its derivatives are known to increase reduced glutathione $(\mathrm{GSH})$ and coenzyme $\mathrm{A}(\mathrm{CoA})$ levels and augment ATP synthesis. All of these functions play an important role for cellular protection against oxidative stress and inflammatory response (1,8-13). Therefore, studies on antineoplastic agents exerting toxic side effects through oxidative stress mechanism have traditionally used Dexp. In this experimental study, we aimed to investigate the protective effects of Dexp against Cis-induced hepatotoxicity.

\section{Materials and methods}

Rat selection. Thirty-two Sprague Dawley rats aged 11 to 12 weeks weighing 230 to 300 grams were obtained from Experimental Animal Research Center of Inonu University, Malatya, Turkey. The rats were fed on standard rat feed and provided water ad libitum. They were kept under laboratory conditions $\left(21 \pm 2^{\circ} \mathrm{C}, \% 60 \pm 5\right.$ moisture and $12: 12 \mathrm{~h}$ light/dark cycle). All procedures applied to the rats complied with the National Health Institute's Guidelines for Animal Research. The experimental groups were formed by the simple randomization technique.

Institutional approvals. This study was approved by Inonu University Faculty of Medicine Animal Research Ethics Committee (2016/A-36). It was funded by Inonu University Scientific Research Project Coordination Unit (Project no. 2016/179).

Experimental design. Thirty-two rats were divided into four groups each containing an equal number of rats $(n=8)$. The study groups were defined as follows: The rats of the control group were not administered anything else than standard rat feed and water. The rats in the Dexp group were administered a single dose intraperitoneal Dexp at a dose of $500 \mathrm{mg} / \mathrm{kg}$ for 3 days (Bepanthene $500 \mathrm{mg}$ vials, Bayer Corp, Istanbul, Turkey) (12). The dosage range at which Dexp exerts its cytoprotective effect has been shown by the previous studies. Hence, we calculated the effective Dexp dose on the basis of the literature studies $(4,8,12)$. Although the duration of Dexp use ranged between 1 and 12 days in the previous experimental studies about the Dexp's cytoprotective effect, we limited that duration to 3 days (12). The rats in the Cis group were administered a single dose of Cis at a dose of $7 \mathrm{mg} / \mathrm{kg}$ only on the first day of the study (Cis 50 mg vials; Kocak Pharma, İstanbul, Turkey) (2,7). The dosage range at which $\mathrm{Cis}$ exerts its cytotoxic (hepatotoxic) effects has been shown by the previous experimental studies $(2,7)$. The rats in the Cis+Dexp group were administered intraperitoneal Dexp at a dose of $500 \mathrm{mg} / \mathrm{kg}$ for three days. One hour after the first Dexp dose a single intraperitoneal dose of $7 \mathrm{mg} / \mathrm{kg}$ Cis was administered. All rats were sacrificed by ketamine hydrochloride (Ketalar 500 mg vials; Pfizer Inc., NY, USA) overdose at the end of the fourth day of the follow-up period. Immediately before the scarification procedure blood samples were collected from the inferior vena cava for biochemical analysis. Hepatectomy was carried out after blood collection, and part of the hepatectomy material was fixated with formalin for histopathological examination and the remaining tissues were stored at $-70^{\circ} \mathrm{C}$ for biochemical analysis.
Biochemical analysis. At the end of study period, the animals were anesthetized and blood samples were withdrawn into evacuated tubes by vena cava inferior puncture. Then the rats were sacrificed and taken their livers. The liver samples were frozen at $-70^{\circ} \mathrm{C}$ until assayed. The liver samples were homogenized in cold phosphate buffer ( $20 \mathrm{mmol}$; pH 7.4; containing protease inhibitor cocktail, BioShop Canada Inc., Burlington, ON, Canada) with a homogenizer (IKA ultra turrax T 25 basic) at $16,000 \mathrm{rpm}$ for $3 \mathrm{~min}$ at $+4^{\circ} \mathrm{C}$. The homogenats were centrifuged at $10,000 \times \mathrm{g}$ for $20 \mathrm{~min}$ at $+4^{\circ} \mathrm{C}$ and the obtained supernatants were used to measure the levels of MDA, GSH, GSH-Px, CAT, total nitrite, IL-1 $\beta$, IL-6, TNF- $\alpha$, TAS, and TOS. The blood samples taken from rats were centrifuged at $2,000 \mathrm{x}$ for $10 \mathrm{~min}$ at $+4^{\circ} \mathrm{C}$ and the obtained serum samples were used to measure the levels of GSH, TAS, TOS, total nitrite, 1-arginine, ADMA, and SDMA. The serum samples were frozen at $-70^{\circ} \mathrm{C}$ until assayed.

Malondialdehyde (MDA) assay. MDA, referred to as thiobarbituric acid reactive substances (TBARS), was measured with thiobarbituric acid at 535 and $520 \mathrm{~nm}$ in spectrophotometer using a microplate reader (Synergy H1; BioTek Instruments, Inc.) as previously described (14). Results were reported as $\mathrm{nmol} / \mathrm{g}$ wet tissue for tissue.

Reduced GSH assay. GSH concentrations in the homogenate and serum samples were measured according to the spectrophotometric Ellman's method (15). Results were reported as $\mathrm{nmol} / \mathrm{g}$ wet tissue for tissue and micromole/l for serum.

Catalase (CAT) activity assay. CAT activity was determined according to the method of Aebi (16) by monitoring the initial rate of disappearance of hydrogen peroxide (initial concentration $10 \mathrm{mM}$ ) at $240 \mathrm{~nm}$ in a spectrophotometer (microplate reader; Synergy H1). Results were reported as constant rate per gram protein $(\mathrm{K} / \mathrm{g}$ protein).

GSH-peroxidase (Px) activity assay. GSH-Px activity was measured according to Paglia and Valentine (17) by monitoring the oxidation of reduced nicotinamide adenine dinucleotide phosphate (NADPH) at $340 \mathrm{~nm}$. Results were reported as units per gram protein (U/g protein).

Protein assay. Protein concentrations of the supernatant samples were measured the method of Lowry et al (18).

NO assay. NO level of the supernatant and serum samples was measured as total nitrite with the spectrophotometric Griess reaction. Because, it was showed that plasma nitrite/nitrate is an index of endogenous NO production $(19,20)$. The procedure was partly adapted from the method described by Ozbek et al (21) Results were reported as nanomole/g wet tissue for tissue and micromole/liter for serum.

Measurement of the supernatant and serum ADMA, SDMA, and L-arginine levels. The supernatant and serum ADMA, SDMA, and L-arginine concentrations were measured with high performance liquid chromatography using commercially available kits (Eureka Laboratory Division s.r.l., Chiaravalle, Italy). The results were expressed as micromole/liter. 
Measurement of the supernatant and serum total antioxidant status (TAS) and total oxidant status (TOS) levels. The supernatant and serum TAS and TOS concentrations were measured with spectrophotometer (microplate reader; Synergy H1) using commercially available kits (Rel Assay Diagnostics, Gaziantep, Turkey). The results were expressed as millimole Trolox Eqv/liter for TAS and micromole $\mathrm{H}_{2} \mathrm{O}_{2}$ Eqv/liter for TOS.

Measurement of the supernatant $I L-1 \beta, I L-6, T N F-\alpha$ levels. The supernatant IL-1 $\beta$, IL-6, TNF- $\alpha$ levels was measured spectrophotometrically using Elabscience Raybiotech commercial kits (microplate reader; Synergy H1).

Oxidative stress index (OSI). The ratio of TOS to TAS was accepted as OSI. The OSI value was calculated according to the following formula: OSI (arbitrary unit)=TOS (micromole H2O2 Eqv/liter)/TAS (millimole Trolox Eqv/liter) (22).

Histopathological analysis. Liver tissue was fixed in $10 \%$ formalin and was embedded in paraffin. Tissue sections were cut at $4 \mu \mathrm{m}$, mounted on slides, stained with hematoxylin and eosin (H\&E) for general liver structure, Periodic Acid Schiff (PAS) to demonstrate the glycogen deposition in hepatocytes and Kupffer cells. The liver damage was semi quantitatively assessed as follows; sinusoidal congestion, and loss of the glycogen deposition in hepatocytes. The sinusoidal congestion, and glycogen loss were scored between $0-3$; 0 was defined as normal liver, 1 was defined as liver damage involving $\leq 25 \%$ of liver, 2 was defined as liver damage involving $25-50 \%$ of liver and 3 was defined as liver damage involving $\geq 50 \%$ of liver. For each criterion, ten fields were examined in X20 objective magnification. In addition, Kupffer cells were counted manually on digital images Leica Q Win analysis system using point counting. For each animal, three sections were used. In each section, 10 fields were randomly chosen at $40 \mathrm{X}$, totaling 30 fields per animal.

Immunohistochemical analysis. After deparaffinization and rehydration procedures, sections were placed in antigen retrieval solution (citrate buffer, $\mathrm{pH}$ 6.0) and boiled in a pressure cooker for $20 \mathrm{~min}$ and cooled to room temperature for $20 \mathrm{~min}$. Then the sections were washed with phosphate-buffered saline (PBS). After washing the sections, 3\% hydrogen peroxide solution was applied to block endogenous peroxide for $15 \mathrm{~min}$ at room temperature and washed with PBS. Then protein block was applied to the sections. The sections were incubated with caspase-3 primary antibody (rabbit polyclonal; Thermo Fisher Scientific, Inc.) for $60 \mathrm{~min}$, then were rinsed in PBS and incubated with biotinylated goat anti polyvalent for $20 \mathrm{~min}$ and streptavidin Px for $20 \mathrm{~min}$ at room temperature. Staining was completed with chromogen+substrate for $10 \mathrm{~min}$, and slides were counter stained with Mayer's hematoxylin for $1 \mathrm{~min}$, rinsed in tap water, and dehydrated. Caspase-3 positive cells stained as brown color. The expression of caspase-3 was assessed as follows: 0, no expression; 1, minimal expression (involving $\leq 25 \%$ of liver); 2 , moderate expression (involving $25-50 \%$ of liver) and 3 , severe expression (involving $\geq 50 \%$ of liver). For this analysis ten fields were examined in objective magnification, $\mathrm{x} 20$. All sections were evaluated using a Leica
DFC280 light microscope and a Leica Q Win Image Analysis system (Leica Micros Imaging Solutions Ltd., Cambridge, $\mathrm{UK})$.

Statistical analysis. The results of the histologic examination were compared using SPSS software (Chicago, IL, USA) version 17 for Microsoft Windows. Mann-Whitney $\mathrm{U}$ (Bonferroni) test was used for comparison between groups. The results of the biochemical analysis were compared using SPSS software (SPSS, Chicago, IL, USA) version 22.0 for Microsoft Windows. Kruskal-Wallis test was used for comparison between groups. When significant differences were determined in Kruskal-Wallis test, pairwise comparisons were carry out using Conover's test. The results are expressed as the med (min-max). $\mathrm{P}<0.05$ was considered to indicate a statistically significant difference.

\section{Results}

\section{Biochemical results}

Tissue biochemical results. As all biochemical parameters measured in the liver tissues showed a nonparametric distribution, Kruskal-Wallis test was used for inter-group comparisons. There were significant inter-group differences with respect to MDA $(\mathrm{P}=0.001)$, GSH $(\mathrm{P}=0.001)$, CAT $(\mathrm{P}=0.001)$, GHS-Px $(\mathrm{P}=0.001)$, Total Nitrite $(\mathrm{P}=0.001)$, TAS $(\mathrm{P}=0.001)$, TOS $(\mathrm{P}=0.001)$, OSI $(\mathrm{P}=0.001)$ and IL-6 $(\mathrm{P}=0.017)$ levels whereas tissue $\mathrm{L}-1 \beta(\mathrm{P}<0.081)$ and TNF- $\alpha(\mathrm{P}<0.322)$ levels were comparable. For groups that were found to have statistical differences, Conover test was applied to find out the different pairs. Significant differences were found between all groups with respect to tissue MDA, CAT and Total Nitrite levels. Whereas there were no significant differences between the Control and Dexp groups in terms of tissue GHS-Px, TOS and OSI, the Cis and Cis+Dexp groups showed significant differences from the other groups. Whereas the Control and Cis groups did not show any significant differences for tissue GSH level, Dexp and Cis+Dexp groups were significantly different from the other groups. Although no significant differences existed between the control and Cis+Dexp groups with regard to tissue TAS level, the Dexp and Cis groups were significantly different from the other groups. A significant difference existed between tissue IL- 6 levels of the Dexp and Cis groups. Table I summarizes the results of the tissue biochemical parameters.

Serum biochemistry results. As all biochemical parameters obtained from the serum samples showed a nonparametric distribution, inter-group comparisons were carried out using the Kruskal-Wallis test. The groups had significant differences with regard to serum GSH $(\mathrm{P}=0.014)$, TAS $(\mathrm{P}=0.003)$, OSI $(\mathrm{P}=0.004)$, Total Nitrite $(\mathrm{P}=0.003)$, L-Arginine $(\mathrm{P}=0.003)$, ADMA $(\mathrm{P}=0.026)$ and SDMA $(\mathrm{P}=0.022)$ levels whereas serum TOS $(\mathrm{P}<0.058)$ levels were similar. Serum biochemistry results were presented on Table II.

\section{Histopathological results}

Hematoxylin and eosin. Liver tissue of the Control and Dexp groups showed entirely normal histological appearance but minimal changes. Sinusoidal congestion was the 
Table I. Comparison of biochemical parameters measured in liver tissue.

\begin{tabular}{|c|c|c|c|c|c|}
\hline Parameters & Group & Median & Minimum & Maximum & $\mathrm{P}$ \\
\hline \multirow[t]{4}{*}{ MDA (nmol/gr wet tissue) } & Control $^{\mathrm{a}}$ & 659.9 & 592.9 & 854.2 & 0.001 \\
\hline & $\operatorname{Dexp}^{b}$ & 512.5 & 197.6 & 629.8 & \\
\hline & $\mathrm{Cis}^{\mathrm{c}}$ & 1334.9 & 783.9 & 1999.9 & \\
\hline & Cis+Dexp ${ }^{\mathrm{d}}$ & 904.5 & 673.3 & 1139 & \\
\hline \multirow[t]{4}{*}{ GSH (nmol/gr wet tissue) } & Control $^{\mathrm{a}}$ & 2035.2 & 1781.9 & 2140.9 & 0.001 \\
\hline & $\operatorname{Dexp}^{\mathrm{b}}$ & 2769.1 & 2602.4 & 3198.6 & \\
\hline & $\mathrm{Cis}^{\mathrm{c}}$ & 1612.1 & 1346.1 & 1865.3 & \\
\hline & Cis+Dexp ${ }^{a}$ & 2019.1 & 1852.5 & 2506.3 & \\
\hline \multirow[t]{4}{*}{ CAT (K/g protein) } & Control $^{\mathrm{a}}$ & 24.1 & 20.1 & 30.3 & 0.001 \\
\hline & $\operatorname{Dexp}^{\mathrm{b}}$ & 51.4 & 48.4 & 57.2 & \\
\hline & $\mathrm{Cis}^{\mathrm{c}}$ & 13.2 & 12.3 & 15.9 & \\
\hline & Cis+Dexp ${ }^{d}$ & 30.7 & 25.3 & 39.2 & \\
\hline \multirow[t]{4}{*}{ GSH-Px (U/g protein) } & Control $^{\mathrm{a}}$ & 101.1 & 90.0 & 118.3 & 0.001 \\
\hline & $\operatorname{Dexp}^{a}$ & 107 & 95.9 & 125.9 & \\
\hline & $\mathrm{Cis}^{\mathrm{b}}$ & 59.8 & 45.4 & 95.47 & \\
\hline & Cis+Dexp ${ }^{a}$ & 89.2 & 71.8 & 108.1 & \\
\hline \multirow[t]{4}{*}{ Tot Nit (nmol/gr wet tissue) } & Control $^{\mathrm{a}}$ & 275.4 & 266.4 & 298.8 & 0.001 \\
\hline & $\operatorname{Dexp}^{b}$ & 349.2 & 288 & 381.6 & \\
\hline & $\mathrm{Cis}^{\mathrm{c}}$ & 248.4 & 216 & 273.6 & \\
\hline & Cis+Dexp ${ }^{d}$ & 298.8 & 266.4 & 324 & \\
\hline \multirow[t]{4}{*}{ TAS (mmol Trolox Eqv/l) } & Control $^{\mathrm{a}}$ & 2.2 & 2.1 & 2.54 & 0.001 \\
\hline & $\operatorname{Dexp}^{\mathrm{b}}$ & 2.5 & 2.4 & 2.6 & \\
\hline & $\mathrm{Cis}^{\mathrm{c}}$ & 1.8 & 1.7 & 1.85 & \\
\hline & Cis+Dexp ${ }^{a}$ & 2.1 & 1.9 & 2.31 & \\
\hline \multirow[t]{4}{*}{$\operatorname{TOS}\left(\mu \mathrm{mol} \mathrm{H} \mathrm{O}_{2} \mathrm{Eqv} / \mathrm{l}\right)$} & Control $^{\mathrm{a}}$ & 26.2 & 19.5 & 33.8 & 0.001 \\
\hline & $\operatorname{Dexp}^{\mathrm{a}}$ & 24.1 & 20.1 & 31.8 & \\
\hline & $\mathrm{Cis}^{\mathrm{b}}$ & 39.1 & 35.2 & 46.4 & \\
\hline & Cis+Dexp ${ }^{c}$ & 33.3 & 26.2 & 35.1 & \\
\hline \multirow[t]{4}{*}{ OSI ( $\mu \mathrm{mol} \mathrm{H}_{2} \mathrm{O}_{2}$ Eqv/mmol Trolox Eqv) } & Control $^{\mathrm{a}}$ & 11.9 & 7.7 & 15.6 & 0.001 \\
\hline & $\operatorname{Dexp}^{a}$ & 9.7 & 7.8 & 13.1 & \\
\hline & $\mathrm{Cis}^{\mathrm{b}}$ & 21.8 & 20.1 & 25.9 & \\
\hline & Cis+Dexp ${ }^{c}$ & 15.5 & 11.5 & 16.8 & \\
\hline \multirow[t]{4}{*}{ IL-1 $\beta(\mathrm{pg} / \mathrm{ml})$} & Control $^{\mathrm{a}}$ & 23.3 & 18.4 & 42.8 & 0.081 \\
\hline & $\operatorname{Dexp}^{a}$ & 16.4 & 12.9 & 67.7 & \\
\hline & $\mathrm{Cis}^{\mathrm{a}}$ & 26.8 & 19.4 & 63.4 & \\
\hline & Cis+Dexp ${ }^{a}$ & 35.9 & 20.5 & 41.7 & \\
\hline \multirow[t]{4}{*}{ IL-6 (pg/ml) } & Control $^{\mathrm{a}}$ & 13.8 & 5.8 & 20.5 & 0.017 \\
\hline & $\operatorname{Dexp}^{a}$ & 11.7 & 4.5 & 20.1 & \\
\hline & $\mathrm{Cis}^{\mathrm{b}}$ & 28.8 & 13.8 & 60.1 & \\
\hline & Cis+Dexp ${ }^{a}$ & 17.1 & 6.3 & 34.6 & \\
\hline \multirow[t]{4}{*}{$\mathrm{TNF}-\alpha(\mathrm{pg} / \mathrm{ml})$} & Control $^{\mathrm{a}}$ & 263.6 & 167.7 & 332.4 & 0.322 \\
\hline & $\operatorname{Dexp}^{a}$ & 237.7 & 141.5 & 300.1 & \\
\hline & $\mathrm{Cis}^{\mathrm{a}}$ & 293.6 & 219.5 & 441.6 & \\
\hline & Cis+Dexp ${ }^{a}$ & 242.4 & 222.4 & 361.9 & \\
\hline
\end{tabular}

${ }^{\mathrm{a}-\mathrm{c}}$ Different superscript letters indicate that there is statistical difference between the groups (stepwise step-down multiple comparisons after significant Kruskal Wallis test; $\mathrm{P}<0.05) .{ }^{\mathrm{a}-\mathrm{C}}$ Same superscript letters indicate that there is no statistical difference between the groups $(\mathrm{P}>0.05)$. Cis, cisplatin; Dexp, dexpanthenol; MDA, malondialdehyde; GSH, reduced glutathione; CAT, catalase; GSH-Px, glutathione peroxidase; Tot Nit, total nitrite; TAS, total antioxidant status; TOS, total oxidant status; OSI, oxidative stress index; ADMA, asymmetric dimethylarginine; SDMA, symmetric dimethylarginine. 
Table II. Comparison of biochemical parameters measured in serum samples.

\begin{tabular}{|c|c|c|c|c|c|}
\hline Parameters & Groups & Median & Minimum & Maximum & $\mathrm{P}$ \\
\hline \multirow[t]{4}{*}{$\mathrm{GSH}(\mu \mathrm{mol} / \mathrm{l})$} & Control $^{\mathrm{a}}$ & 15.9 & 15.7 & 16,3 & \multirow[t]{4}{*}{0.014} \\
\hline & $\operatorname{Dexp}^{\mathrm{b}}$ & 19.2 & 17.3 & 19,4 & \\
\hline & $\mathrm{Cis}^{\mathrm{a}}$ & 15.9 & 14.3 & 17,1 & \\
\hline & Cis+Dexp ${ }^{b}$ & 17.7 & 16.3 & 19,1 & \\
\hline \multirow[t]{4}{*}{ TAS (mmol Trolox Eqv/l) } & Control $^{\mathrm{a}}$ & 1.3 & 1.3 & 1.3 & \multirow[t]{4}{*}{0.003} \\
\hline & $\operatorname{Dexp}^{\mathrm{b}}$ & 1.7 & 1.4 & 1.9 & \\
\hline & $\mathrm{Cis}^{\mathrm{c}}$ & 1.1 & 1.1 & 1.1 & \\
\hline & Cis+Dexp ${ }^{b}$ & 1.6 & 1.4 & 1.6 & \\
\hline \multirow[t]{4}{*}{ TOS $\left(\mu \mathrm{mol} \mathrm{H}_{2} \mathrm{O}_{2}\right.$ Eqv/l) } & Control $^{\mathrm{a}}$ & 41.2 & 38.8 & 42.8 & \multirow[t]{4}{*}{0.058} \\
\hline & $\operatorname{Dexp}^{a}$ & 35.2 & 32.4 & 38.4 & \\
\hline & $\operatorname{Cis}^{\mathrm{a}}$ & 49.6 & 33.6 & 55.6 & \\
\hline & Cis+Dexp ${ }^{a}$ & 44.4 & 37.6 & 44.8 & \\
\hline \multirow[t]{4}{*}{$\mathrm{OSI}\left(\mu \mathrm{mol} \mathrm{H}_{2} \mathrm{O}_{2}\right.$ Eqv/mmol trolox Eqv) } & Control $^{\mathrm{a}}$ & 32.6 & 30.6 & 32.9 & \multirow[t]{4}{*}{0.004} \\
\hline & $\operatorname{Dexp}^{b}$ & 20.1 & 16.8 & 27.9 & \\
\hline & $\mathrm{Cis}^{\mathrm{a}}$ & 47.1 & 30.9 & 54.3 & \\
\hline & Cis+Dexp ${ }^{b}$ & 27.2 & 26.9 & 27.3 & \\
\hline \multirow[t]{4}{*}{ Tot Nit $(\mu \mathrm{mol} / 1)$} & Control $^{\mathrm{a}}$ & 33.9 & 32.9 & 34.8 & \multirow[t]{4}{*}{0.003} \\
\hline & $\operatorname{Dexp}^{b}$ & 45.2 & 44.3 & 48.0 & \\
\hline & $\mathrm{Cis}^{\mathrm{a}}$ & 32.5 & 31.1 & 33.9 & \\
\hline & Cis+Dexp ${ }^{c}$ & 36.7 & 35.8 & 37.7 & \\
\hline \multirow[t]{4}{*}{ L-Arjinin $(\mu \mathrm{mol} / \mathrm{l})$} & Control $^{\mathrm{a}}$ & 0.5 & 0.3 & 0.7 & \multirow[t]{4}{*}{0.003} \\
\hline & $\operatorname{Dexp}^{a}$ & 0.4 & 0.3 & 0.5 & \\
\hline & $\mathrm{Cis}^{\mathrm{b}}$ & 6.2 & 5.8 & 6.8 & \\
\hline & Cis+Dexp ${ }^{c}$ & 5.5 & 5.3 & 5.6 & \\
\hline \multirow[t]{4}{*}{$\mathrm{ADMA}(\mu \mathrm{mol} / \mathrm{l})$} & Control $^{\mathrm{a}}$ & 0.2 & 0,2 & 0.3 & \multirow[t]{4}{*}{0.026} \\
\hline & $\operatorname{Dexp}^{a}$ & 0.4 & 0,2 & 0.4 & \\
\hline & $\mathrm{Cis}^{\mathrm{b}}$ & 0.5 & 0,2 & 0.6 & \\
\hline & Cis+Dexp ${ }^{a}$ & 0.2 & 0,1 & 0.3 & \\
\hline \multirow[t]{4}{*}{ SDMA $(\mu \mathrm{mol} / \mathrm{l})$} & Control $^{\mathrm{a}}$ & 0.5 & 0.4 & 0.5 & \multirow[t]{4}{*}{0.022} \\
\hline & $\operatorname{Dexp}^{a}$ & 0.4 & 0.3 & 0.5 & \\
\hline & $\mathrm{Cis}^{\mathrm{b}}$ & 0.6 & 0.5 & 0.7 & \\
\hline & Cis+Dexp ${ }^{a}$ & 0.4 & 0.4 & 0.5 & \\
\hline
\end{tabular}

${ }^{\mathrm{a}-\mathrm{c}}$ Different superscript letters indicate that there is statistical difference between the groups (Stepwise step-down multiple comparisons after significant Kruskal Wallis test; $\mathrm{P}<0.05){ }^{\mathrm{a}-\mathrm{c}}$ Same superscript letters indicate that there is no statistical difference between the groups $(\mathrm{P}>0.05)$. Cis, cisplatin; Dexp, dexpanthenol; GSH, reduced glutathione; TAS, total antioxidant status; TOS, total oxidant status; OSI, oxidative stress index; Tot Nit, total nitrite; ADMA, asymmetric dimethylarginine; SDMA, symmetric dimethylarginine.

most prominent alteration in the Cis group. Furthermore, hepatocytes with eosinophilic cytoplasm and pyknotic nuclei were detected in some sections. The Cis+Dexp group showed similarities with the Cis group in terms of histological changes. Table III shows congestion scores of the study groups.

$P A S$. In the Control and Dexp groups, glycogen and Kupffer cells (Fig. 1a and b) in the hepatocyte cytoplasm were stained with pink and purple stain. As compared with the controls, the Cis group showed a reduced amount of glycogen accumulation in hepatocytes $(\mathrm{P}<0.001)$. Additionally, the Cis group, as compared to the Control and Dexp groups, had a significantly increased number of Kupffer cells (Fig. 1c) $(\mathrm{P}<0.001)$. In the
Dexp group, glycogen loss in hepatocytes was significantly reduced (Fig. 2d) $(\mathrm{P}<0.001)$. Furthermore, Cis+Dexp group showed a significant reduction in the number of Kupffer cells as compared to the Cis group. (Fig. 1d) $(\mathrm{P}<0.001)$.

Immunohistochemical results. The control and Dexp groups had no caspase-3 expression in the tissue sections except for a few hepatocytes (Fig. 2a and b). On the other hand, there was a significant increase in the caspase-3 expression in the Cis group $(\mathrm{P}<0.001)$ (Fig. 2c). That group also demonstrated an increased caspase-3 staining intensity. However, Cis+Dexp group had a significant decrease in the caspase-3 expression $(\mathrm{P}<0.001)$ (Fig. 2d). Table III shows the immunohistochemical staining scores of the study groups. 
Table III. Comparison of groups interms of histopathological and immunhistochemical findings.

\begin{tabular}{lcccc}
\hline Parameters & Control & Dexp & Cis & Cis+Dexp \\
\hline Congestion & & & & \\
Median (min-max) & $1.0(0.0-2.0)$ & $1.0(0.0-2.0)$ & $1.0(0.0-3.0)^{\mathrm{a}}$ & $1.0(0.0-3.0)^{\mathrm{c}}$ \\
Mean \pm SD & $0.56 \pm 0.58$ & $0.70 \pm 0.60$ & $1.13 \pm 0.66$ & $1.30 \pm 0.60$ \\
Glycogen loss & & & & \\
Median (min-max) & $0.0(0.0-3.0)$ & $0.0(0.0-3.0)$ & $2.0(0.0-3.0)^{\mathrm{a}}$ & $1.0(0.0-2.0)^{\mathrm{b}}$ \\
Mean \pm SD & $0.57 \pm 0.69$ & $0.49 \pm 0.83$ & $2.09 \pm 0.65$ & $0.69 \pm 0.65$ \\
Kupffer cells & & & & $1.0(0.0-8.0)^{\mathrm{b}}$ \\
Median (min-max) & $1.0(0.0-5.0)$ & $1.0(0.0-6.0)$ & $5.0(0.0-20.0)^{\mathrm{a}}$ & $1.63 \pm 1.60$ \\
Mean \pm SD & $1.35 \pm 1.30$ & $1.22 \pm 1.50$ & $5.46 \pm 3.79$ & $0.0(0.0-1.0)^{\mathrm{b}}$ \\
Caspase-3 expression & & & & $0.12 \pm 0.32$ \\
Median (min-max) & $0.0(0.0-1.0)$ & $0.0(0.0-1.0)$ & $1.0(0.0-3.0)^{\mathrm{a}}$ & $1.02 \pm 0.85$ \\
Mean \pm SD & $0.15 \pm 0.36$ & $0.33 \pm 0.47$ & & \\
\hline
\end{tabular}

${ }^{a}$ Cis vs. Control group $(\mathrm{P}<0.001){ }^{\mathrm{b}} \mathrm{Cis}$ vs. Cis $+\mathrm{Dex}(\mathrm{P}<0.001){ }^{\mathrm{c}} \mathrm{Cis}$ vs. Cis $+\mathrm{Dex}(\mathrm{P}<0.079)$. Cis, cisplatin; Dexp, dexpanthenol.

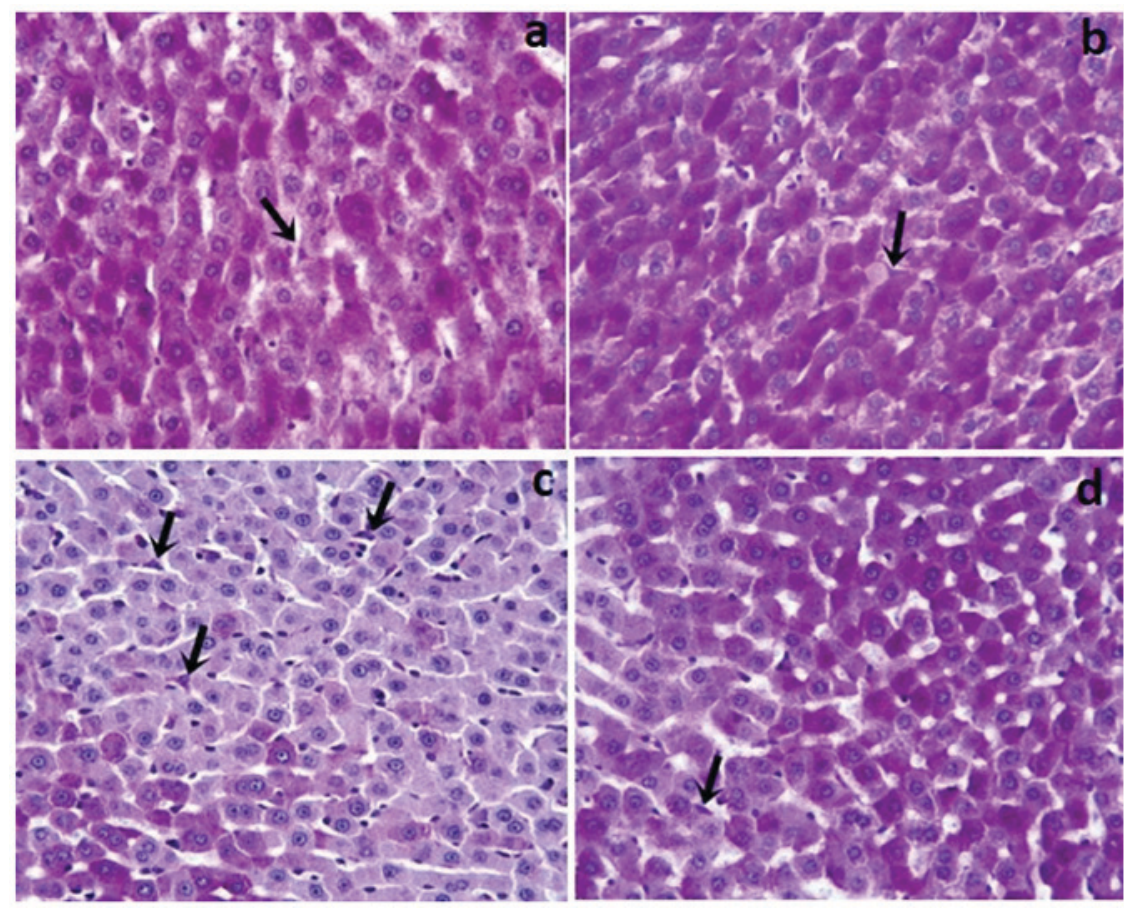

Figure 1. (a) Control and (b) Dexp groups; PAS positive reaction show a magenta staining in which Kupffer cells were present in the lumen or near the wall of sinusoid (arrows). (c) Cis group; an increased number of Kupffer cells (arrows) were indicated. (d) Cis+ Dexp group; a decreased number of Kupffer cells (arrows) were indicated (magnification, $\mathrm{x} 40$ ). Cis, cisplatin; Dexp, dexpanthenol.

\section{Discussion}

Although several experimental studies have reported hepatotoxicity occurring with high doses of Cis, some others have indicated that the former may occur even with a single dose or low prolonged doses use of Cis $(1,6)$. As Cis is a small molecule, it easily passes through the cell membrane to reach cell nucleus and alter DNA structure (5). Although the pathophysiological mechanism of Cis-induced hepatotoxicity has yet to be fully understood, recent studies have shown that a considerable proportion of its toxic side effects originate from oxidative stress and apoptosis $(1,5)$. Studies on Cis toxicity showing reduced hepatic GSH levels and increased hepatic MDA levels have corroborated the notion that Cis toxicity is linked with oxidative stress of hepatocytes (5). Therefore, experimental studies have so far employed many antioxidants, free radical scavengers, and natural herbal extracts considered to have protective properties against Cis-associated cytotoxicity.

Oxidative stress may be defined as overproduction of reactive oxygen species and/or failure of antioxidant mechanisms (3). Reactive oxygen species produced by normal metabolism are eliminated in the liver by certain reactions in 


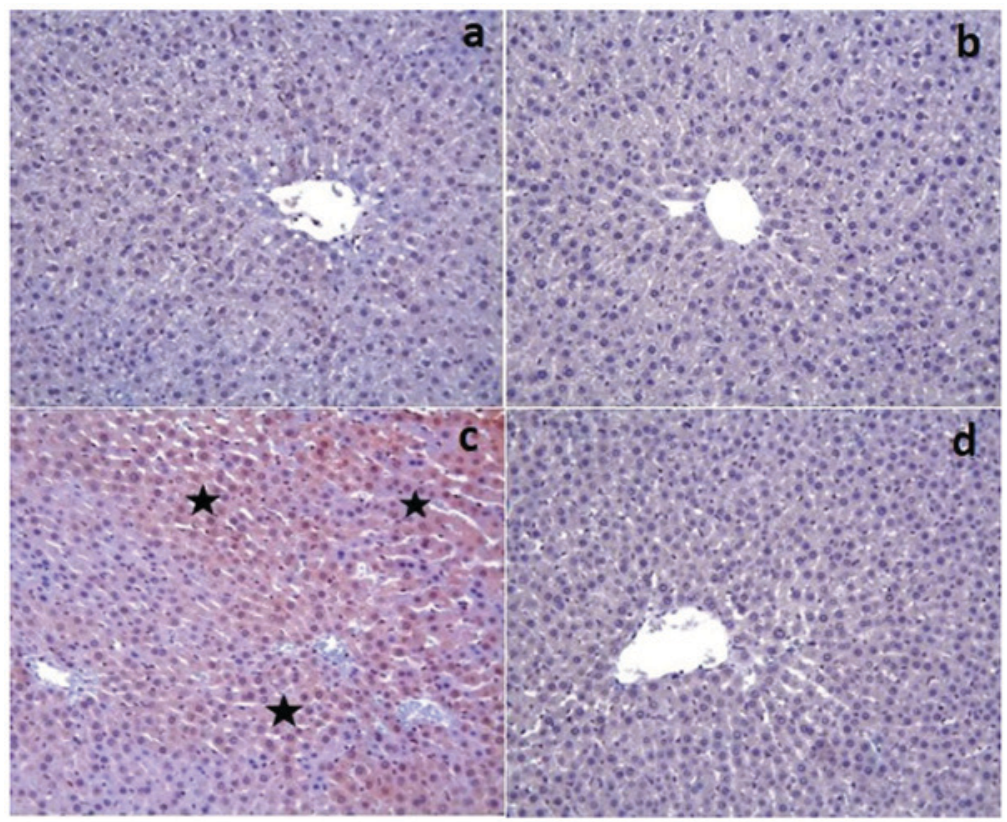

Figure 2. (a) Control and (b) Dexp groups; caspase-3 expression was observed as negative. (c) Cis group; caspase-3 (+) cells were distinguished by brown cytoplasm (stars). (d) Cis+Dexp group; hepatocytes were not stained with caspase-3 (magnification, x20). Cis, cisplatin; Dexp, dexpanthenol.

which enzymes such as superoxide dismutase, catalase, GSH Pxs, and peroxiredoxin are involved $(5,23)$. When the liver is exposed to oxidative stress as in Cis-induced hepatotoxicity, liver cells encounter large quantities of reactive oxygen species that overwhelm their detoxification capacity. Reactive oxygen species then cause hepatocyte injury by injuring DNA (increased cell death, reduced proliferation), protein oxidation (growth factor inhibition, reduced enzymatic functions), lipid peroxidation (inflammation, radical formation) and direct action on signal pathways (transcription factor activation, reduced angiogenesis, reduced NO level) $(5,23)$.

In the present experimental study model, we aimed to investigate if Dexp would exert any cytoprotective and antioxidant effect on Cis-induced hepatotoxicity. According to the most recent literature data, an important percentage of Cis related side effects occur through oxidative stress pathways. Based on this information, we studied several oxidative stress parameters in liver tissue and blood samples. The levels of tissue antioxidant parameters (GSH, CAT, GSH-Px, TAS) were significantly greater in the Cis+ Dexp group compared to the Cis group. In contrast, the levels of oxidative stress products (MDA, TOS, OSI) were significantly greater in the Cis group than the Cis+Dexp group. Similarly, serum GSH and TAS levels were greater in the Cis+Dexp group whereas serum TOS and L-Arginine levels were greater in the Cis group. These results suggest that Dexp minimizes Cis's hepatotoxic effect by intensifying antioxidant mechanisms.

ADMA and SDMA are toxic non-proteinogenic amino acids formed by post-translational modification. These toxic dimethylarginines were first detected in human urine in 1970. Both of them suppress NO production by inhibiting the Nitric Oxide Synthase (NOS) enzyme. Clinical and experimental studies have shown that ADMA and SDMA play a role in the pathophysiological mechanism of endothelial dysfunction, atherosclerosis, oxidative stress, inflammation, and apoptosis (24). ADMA disintegrates NOS into its isoenzymes to produce superoxide radicals that are involved in oxidative stress (24). SDMA, unlike ADMA, induces pathways involved in the production of free oxygen species and has therefore proinflammatory and prooxidant properties (24). In our study the Cis+Dexp group had significantly lower blood ADMA, SDMA, and L-Arginine levels than the Cis group. In contrast, the Cis+Dexp group had a significantly higher total nitrite levels than the Cis group. These results suggest that since Dexp reduced ADMA and SDMA levels, the NOS enzyme was not inhibited and Arginine was converted into NO molecule, which reduced blood arginine level in the Cis+Dexp group.

Another important point to stress is the mechanism of the alterations of blood and tissue NO levels. A general consensus exists that $\mathrm{NO}$ behaves differently in physiological and pathological conditions. It is known that many hepatotoxic drugs and chemical substances increase hepatic NO production by inhibiting iNOS enzyme and are converted to peroxynitrite by reacting with NO's superoxide anion, causing hepatic injury via nitrous active stress (25). In this regard, our results do not overlap with the literature data. This is because both tissue and blood total nitrite levels were significantly higher in the Dexp and Cis+Dexp groups compared to the Cis group. Moreover, total nitrite levels were even higher in the Cis group than the control group. That is, in contrast with the literature data, the findings of the present study indicate that antioxidant agents increased NO levels rather than reducing them. To our opinion, this finding may be related to a reduction of ADMA and SDMA levels by Dexp, as we pointed above. Nevertheless, in any case, this point needs to be confirmed by other studies.

Cytokines playing a role in both proinflammatory and anti-inflammatory stages of inflammation are the major molecules that have been investigated by inflammation models $(11,26)$. As the liver hosts receptors belonging to many different varieties of cytokines, it has been widely 
studied in inflammation models. Reactive oxygen species produced during oxidative stress may further augment Cis's cytotoxic effects in the liver by increasing nuclear kappa factor $\mathrm{B}$ expression and release of proinflammatory cytokines (particularly IL-1 $\beta$, TNF- $\alpha$, and IL-6) $(2,26)$. We aimed to investigate how proinflammatory cytokines behave in Cis-induced hepatotoxicity and how Dexp affects their tissue levels. Accordingly, although tissue IL- 6 and TNF- $\alpha$ levels were higher in the Cis group compared to the Cis+Dexp group, this difference did not reach statistical significance. However, these findings show parallelism with the literature data with regard to their mathematical results (11). In contrast, tissue IL-1 $\beta$ level was found lower in the Cis group than the Cis+Dexp group. This finding about IL- $1 \beta$ contradicts with the literature data. To our opinion, this contradiction should be corroborated or refuted by future studies.

We discussed above that an important proportion of Cis's side effects occur through oxidative stress pathways. Another mechanism responsible for the genesis of toxic side effects is apoptosis (1). Increased intracellular levels of reactive oxygen species result in DNA injury in the cell nucleus, and when that injury could not be repaired, both proliferation is limited and apoptosis is augmented (23). Many experimental ischemia reperfusion injury and hepatotoxicity models studied the relationship between antioxidant or free radical scavenging agents and apoptosis by both immunohistochemical staining techniques (active caspase-3, split PARP, TUNEL) and tissue/blood biochemical parameters (IL-6, TNF- $\alpha$, caspase-3 activity, DNA fragmentation) $(1,2)$. We studied immunohistochemically caspase-3 expression to assess apoptosis. In the Cis+Dexp group caspase-3 expression was significantly lower than in the Cis group. The overall findings of our study suggest that Dexp reduced apoptosis both by directly eliminating reactive oxygen species that accelerate apoptosis and by reducing the level of the ADMA molecule that induces apoptosis (27).

We would like to mention some points that limited us in this experimental study. The first limiting factor was that we did not studied serum and tissue parameters indicative of nephrotoxicity although the latter is the main most serious side effect of Cis (28). In the present study we had the opportunity to show both the nephrotoxic effects of Cis and the nephroprotective effects of Dexp (29). However, as the study designs solely focused on the liver, renal effects were unfortunately ignored. The second limiting factor was the absence of the determination of AST, ALT, ALP, and bilirubin levels, which are directly indicative of hepatic injury, although many tissue and serum parameters indicative of oxidative stress, antioxidant response, and apoptosis. The previous experimental studies examining the hepatotoxic effects of Cis showed marked alterations in ALT, AST, and ALP levels (28).

As far as we know, this is the first study in the literature that specifically studied the protective effect of Dexp against Cis-induced hepatotoxicity. Hence, it is clear that the findings of the present study need to be supported by other studies designed with the same model. In conclusion, in this experimental study model we demonstrated that Dexp exerted a hepatoprotective, antioxidant, and antiapoptotic action; in other words, it minimized Cis-induced hepatotoxicity.

\section{Acknowledgements}

Not applicable.

\section{Funding}

The present study was supported by the Inonu University Scientific Research Project Coordination Unit (grant no. 2016/179).

\section{Availability of data and materials}

The datasets used and/or analyzed during the current study are available from the corresponding author on reasonable request.

\section{Authors' contributions}

YB, SA, HP and YT designed and directed the experiments. YB, SA, OO and YT performed the experiments. MEE, ZA and YT performed biochemical analysis. NV performed histopathological analysis. SA performed the statistical analysis. SA wrote the manuscript. YB, SA, HP and YT reviewed and edited the manuscript. All authors read and approved the final manuscript.

\section{Ethics approval and consent to participate}

The animal use protocol was reviewed and approved by the Inonu University Faculty of Medicine Animal Research Ethics Committee (2016/A-36). All animals received humane care in compliance with the Guide for the Care and Use of Laboratory Animals published by the National Institutes of Health.

\section{Patient consent for publication}

Not applicable.

\section{Competing interests}

The authors declare that they have no competing interests.

\section{References}

1. Cagin YF, Atayan Y, Sahin N, Parlakpinar H, Polat A, Vardi N, Tagluk ME, Tanbek K and Yildiz A: Beneficial effects of dexpanthenol on mesenteric ischemia and reperfusion injury in experimental rat model. Free Radic Res 50: 354-365, 2016.

2. Cure MC, Cure E, Kalkan Y, Kırbaş A, Tümkaya L, Yılmaz A, Türkyılmaz AK, Şehitoğlu İ and Yüce S: Infliximab modulates cisplatin-induced hepatotoxicity in rats. Balkan Med J 33: 504-511, 2016.

3. Karale S and Kamath JV: Effect of daidzein on cisplatin-induced hematotoxicity and hepatotoxicity in experimental rats. Indian J Pharmacol 49: 49-54, 2017.

4. Toplu Y, Sapmaz E, Parlakpinar H, Kelles M, Kalcioglu MT, Tanbek K and Kizilay A: The effect of dexpanthenol on ototoxicity induced by cisplatin. Clin Exp Otorhinolaryngol 9: 14-20, 2016.

5. Al-Malki AL and Sayed AA: Thymoquinone attenuates cisplatin-induced hepatotoxicity via nuclear factor kappa- $\beta$. BMC Complement Altern Med 14: 282, 2014.

6. Astolfi L, Ghiselli S, Guaran V, Chicca M, Simoni E, Olivetto E, Lelli $\mathrm{G}$ and Martini A: Correlation of adverse effects of cisplatin administration in patients affected by solid tumours: A retrospective evaluation. Oncol Rep 29: 1285-1292, 2013. 
7. Koyuncu I, Kocyigit A, Gonel A, Arslan E and Durgun M The protective effect of naringenin-oxime on cisplatin-induced toxicity in rats. Biochem Res Int 2017: 9478958, 2017.

8. Ermis H, Parlakpinar H, Gulbas G, Vardi N, Polat A, Cetin A Kilic T and Aytemur ZA: Protective effect of dexpanthenol on bleomycin-induced pulmonary fibrosis in rats. Naunyn Schmiedebergs Arch Pharmacol 386: 1103-1110, 2013.

9. Karadag A, Ozdemir R, Kurt A, Parlakpinar H, Polat A, Vardi N, Taslidere E and Karaman A: Protective effects of dexpantheno in an experimental model of necrotizing enterocolitis. J Pediatr Surg 50: 1119-1124, 2015.

10. Soylu Karapinar O, Pinar N, Ozgür T, Özcan O, Bayraktar HS, Kurt RK and Nural O: The protective role of dexpanthenol on the endometrial implants in an experimentally induced rat endometriosis model. Reprod Sci 24: 285-290, 2017.

11. Li-Mei W, Jie T, Shan-He W, Dong-Mei M and Peng-Jiu Y: Anti-inflammatory and Anti-oxidative Effects of Dexpanthenol on Lipopolysaccharide Induced Acute Lung Injury in Mice. Inflammation 39: 1757-1763, 2016.

12. Sen H, Deniz S, Yedekci AE, Inangil G, Muftuoglu T, Haholu A and Ozkan S: Effects of dexpanthenol and N-acetylcysteine pretreatment in rats before renal ischemia/reperfusion injury. Ren Fail 36: 1570-1574, 2014.

13. Uysal HB, Dagli B, Yilmaz M, Kahyaoglu F, Gokcimen A Omurlu IK and Demirci B: Protective effects of dexpanthenol against acetaminophen-induced hepatorenal damage. Biomed Res 28: 740-749, 2017.

14. Mihara M and Uchiyama M: Determination of malonaldehyde precursor in tissues by thiobarbituric acid test. Anal Biochem 86 271-278, 1978

15. Ellman GL: Tissue sulphydryl groups. Arch Biochem Biophys 82 : 70-77, 1959.

16. Aebi H: In Bergmeter HU (eds): Methods in enzymatic analysis, Weinheim, Verlag Chemie 3: 273-282, 1982.

17. Paglia D and Valentine WN: Studies on the quantitative and qualitative charecterization of erythrocyte glutathione peroxidase. J Lab Clin Med 70: 158-169, 1967.

18. Lowry OH, Rosenbrough NJ, Farr AL and Randall RJ: Protein measurement with the folin phenol reagent. J Biol Chem 193 $265-275,1951$

19. Jungersten L, Edlund A, Petersson AS and Wennmalm A: Plasma nitrate as an index of nitric oxide formation in man: Analyses of kinetics and confounding factors. Clin Physiol 16: 369-379, 1996.
20. Zeballos GA, Bernstein RD, Thompson CI, Forfia PR, Seyedi N, Shen W, Kaminiski PM, Wolin MS and Hintze TH: Pharmacodynamics of plasma nitrate/nitrite as an indication of nitric oxide formation in conscious dogs. Circulation 91: 2982-2988, 1995.

21. Ozbek E, Turkoz Y, Gokdeniz R, Davarci M and Ozugurlu F: Increased nitric oxide production in the spermatic vein of patients with varicocele. Eur Urol 37: 172-175, 2000.

22. Erel O: A new automated colorimetric method for measuring total oxidant status. Clin Biochem 38: 1103-1111, 2005.

23. Auten RL and Davis JM: Oxygen toxicity and reactive oxygen species: the devil is in the details. Pediatr Res 66: 121-127, 2009

24. Tain YL and Hsu CN: Toxic dimethylarginines: Asymmetric Dimethylarginine (ADMA) and Symmetric Dimethylarginine (SDMA). Toxins (Basel) 9: E92, 2017.

25. Singh H, Sidhu S, Chopra K and Khan MU: The novel role of $\beta$-aescin in attenuating $\mathrm{CCl} 4$-induced hepatotoxicity in rats. Pharm Biol 55: 749-757, 2017.

26. Kandil YI, Maraqa AD, Oriquat GA and Shraideh ZA: Resveratrol pretreatment reduces circulating inflammatory interleukins in CCl4-induced hepatotoxicity rats. Bulletin Faculty Pharm Cairo Univ 55: 319-323, 2017.

27. Ye S, Zhou X2, Lin J and Chen P: Asymmetric dimethylarginine induced apoptosis and dysfunction of endothelial progenitor cells: Role of endoplasmic reticulum stress pathway. Biomed Res Int 2017: 6395601, 2017.

28. Pezeshki Z, Khosravi A, Nekuei M, Khoshnood S, Zandi E, Eslamian M, Talebi A, Emami SN and Nematbakhsh M: Time course of cisplatin-induced nephrotoxicity and hepatotoxicity. J Nephropathol 6: 163-167, 2017.

29. Dogan EE, Erkoc R, Ekinci I, Hamdard J, Doner B, Cikrikcioglu MA, Karatoprak C, Coban G, Ozer OF and Kazancioglu R: Protective effect of dexpanthenol against nephrotoxic effect of amikacin: An experimental study. Biomed Pharmacother 89: 1409-1414, 2017.

This work is licensed under a Creative Commons Attribution-NonCommercial-NoDerivatives 4.0 International (CC BY-NC-ND 4.0) License. 